\title{
Saúde mental de mulheres em privação de liberdade: a percepção delas
}

\author{
Mental health of women in deprivation of liberty: their perception \\ Salud mental de las mujeres privadas de libertad: su percepción
}

Recebido: 24/08/2021 | Revisado: 29/08/2021 | Aceito: 01/09/2021 | Publicado: 05/09/2021

\author{
Andreza Erdmann Furtado \\ ORCID: https://orcid.org/0000-0001-8500-3531 \\ Universidade Federal de Pelotas, Brasil \\ E-mail: deza_ef@hotmail.com \\ Michele Mandagará de Oliveira \\ ORCID: https://orcid.org/0000-0002-7914-9339 \\ Universidade Federal de Pelotas, Brasil \\ E-mail: mandagara@ hotmail.com \\ Lieni Fredo Herreira \\ ORCID: https://orcid.org/0000-0003-2069-3839 \\ Universidade Federal de Pelotas, Brasil \\ E-mail: lieniherreiraa@hotmail.com \\ Karine Langmantel Silveira \\ ORCID: https://orcid.org/0000-0002-2598-5278 \\ Universidade Federal de Pelotas, Brasil \\ E-mail: kaa_langmantel@hotmail.com \\ Paola de Oliveira Camargo \\ ORCID: https://orcid.org/0000-0002-9169-7602 \\ Universidade Federal de Pelotas, Brasil \\ E-mail: paolacamargo01@ hotmail.com \\ Kauana Flores da Cunha \\ ORCID: https://orcid.org/0000-0003-4221-0033 \\ Universidade Federal de Pelotas, Brasil \\ E-mail: uanaflores@yahoo.com.br \\ Carin Vieira Weiss \\ ORCID: https://orcid.org/0000-0002-1782-2735 \\ Universidade Federal de Pelotas, Brasil \\ E-mail: carin_weiss@hotmail.com \\ Maria Leticia Benelli Rodriguez \\ ORCID: https://orcid.org/0000-0003-3445-2737 \\ Universidad de la Republica Oriental del Uruguay, Uruguay \\ E-mail: lebenro@gmail.com
}

\begin{abstract}
Resumo
O presente artigo tem como objetivo conhecer a percepção de mulheres em privação de liberdade acerca de sua saúde mental. Foi realizado um estudo descritivo de abordagem qualitativa, utilizando entrevistas semiestruturadas que foram gravadas com oito mulheres privadas de liberdade em regime fechado em um presídio no interior do sul do país. Observamos neste estudo que as mulheres privadas de liberdade vivenciam sentimentos, como solidão, angústia, saudade, preocupação, irritação, medo e isolamento, durante este momento, tendo um forte impacto em sua saúde mental, observou-se pensamentos e atos suicidas. As mulheres desta pesquisa apresentam diferentes redes de apoio durante a privação de liberdade, indo de familiares e amigos presentes até ao abandono destes. A relação entre essas mulheres vista como saudável, elas relatam seres prestativas umas com as outras, e algumas disseram que restringir ao necessário a conversa com as colegas para manter a boa convivência e evitar conflitos. Como forma de distração durante o encarceramento elas realizam atividades através de um projeto, também relataram assistir TV, rádio e realizar a limpeza da cela, porém elas expõem que seria importante a realização de outras atividades, principalmente profissionalizantes e educacionais, e também atividades de promoção a sua saúde. Assim, observa-se o quanto é necessário um acompanhamento multiprofissional com olhar sob a saúde integral e educação dessas mulheres. Palavras-chave: Saúde mental; Mulher; Liberdade; Cárcere.
\end{abstract}

\begin{abstract}
This article aims to understand the perception of women deprived of freedom about their mental health. A descriptive study with a qualitative approach was carried out, using semi-structured interviews that were recorded with eight women deprived of their freedom in a closed regime in a prison in the interior of the south of the country. We observed in this study that women deprived of freedom experience feelings such as loneliness, anguish, homesickness, worry, irritation, fear and isolation. During this moment, having a strong impact on their mental health, suicidal
\end{abstract}


thoughts and acts were observed. The women in this research have different support networks during the deprivation of freedom, ranging from family members and friends present to their abandonment. The relationship between these women is seen as healthy, they report being helpful to each other, and some said that they restrict the conversation with their colleagues to what is necessary to maintain a good relationship and avoid conflicts. As a form of distraction during incarceration, they carry out activities through a project, they also reported watching TV, radio and cleaning the cell, but they stated that it would be important to carry out other activities, mainly professional and educational, and also promotional activities your health. Thus, it is observed how much is necessary a multidisciplinary monitoring with a view to the comprehensive health and education of these women.

Keywords: Mental health; Woman; Freedom; Prison.

\section{Resumen}

Este artículo tiene como objetivo comprender la percepción de las mujeres privadas de libertad sobre su salud mental. Se realizó un estudio descriptivo con abordaje cualitativo, mediante entrevistas semiestructuradas que fueron grabadas a ocho mujeres privadas de libertad en régimen cerrado en una cárcel del interior del sur del país. Observamos en este estudio que las mujeres privadas de libertad experimentan sentimientos como soledad, angustia, nostalgia, preocupación, irritación, miedo y aislamiento, durante este tiempo, teniendo un fuerte impacto en su salud mental, se observaron pensamientos y actos suicidas. Las mujeres de esta investigación cuentan con diferentes redes de apoyo durante la privación de libertad, que van desde familiares y amigos presentes hasta su abandono. La relación entre estas mujeres es vista como saludable, reportan ayudarse mutuamente, y algunas dijeron que restringen la conversación con sus colegas a lo necesario para mantener una buena relación y evitar conflictos. Como forma de distração durante o encarceramento elas realizam atividades através de um projeto, também relataram assistir tv, radio e realizar a limpeza da cela, porém elas expõem que seria importante a realização de outras atividades, principalmente profissionalizantes e educacionais, e também atividades de promoção Tu salud. Así, se observa cuánto es necesario un seguimiento multidisciplinario con miras a la salud y educación integral de estas mujeres.

Palabras clave: Salud mental; Mujer; Libertad; Prisión.

\section{Introdução}

A privação de liberdade é uma situação que poucas vezes é imaginada pelas pessoas. A liberdade se apresenta como um direito previsto na Declaração Universal dos Direitos Humanos, na qual prevê que "todo ser humano tem direito à vida, à liberdade e a segurança pessoal". No entanto, quando o indivíduo infringe as leis, a punição é dada com a privação de liberdade, que de acordo com a Constituição Federal do Brasil de 1988, a pena deverá ser cumprida em instituições distintas correspondentes ao delito, idade e sexo, assegurando respeito a integralidade física e moral (Stefano, 2016).

O Brasil está classificado em $3^{\circ}$ lugar entre os países com maior número de população prisional, atrás apenas dos Estados Unidos e da China, conforme aponta a 12ª edição da Lista Mundial da População Carcerária. Em relação a população feminina em privação de liberdade no país, observou-se crescimento notoriamente significativo de cerca de $560 \%$ entre os anos de 2000 e 2014 (Walmsley, 2018; Ferrari, 2019).

O perfil das mulheres que constituem a população prisional em sua maioria é caracterizado por adultas jovens, solteiras, negras, mães de em média 3 filhos, com baixo nível de escolaridade, sem estabilidade trabalhista ou trabalhadoras em cargos de baixa qualificação e com salários inferiores. Apresentam também precariedade no vínculo familiar, baixa sociabilidade e acesso à saúde e educação e histórias marcadas por diversas formas de violência (Santos, 2017; Gusmão, 2019; Silva, 2020).

A mulher em sua forma e gênero carrega diversas particularidades consigo e sofre diversos tipos de preconceitos e discriminações, estas se intensificam quando a mulher se encontra em situação de cárcere. Devido a isto, a saúde mental das mulheres em privação de liberdade deve ser atentada pela equipe de saúde atuante no sistema, por esta carregar diversos fatores pré e pós cárcere que podem desencadear algum tipo de transtorno mental.

As mulheres em situação de cárcere têm grande probabilidade de desenvolver algum tipo de transtorno mental, decorrentes de sua antiga e atual situação e o ambiente no qual está inserida. O ambiente carcerário insalubre, a limitação de recursos, a superlotação e as vivências anteriores destas mulheres podem causar implicações psicológicas consideráveis, 
apresentando-se como fatores de risco para o desenvolvimento de transtornos mentais, podendo levar a situações e comportamentos autodestrutivos. Destaca-se a maior prevalência de transtornos mentais em mulheres do que em homens em situação de cárcere, justamente pelos encargos de vida pregressa, como violência doméstica e situação prévia de vulnerabilidade, e as implicações que o próprio cárcere gera (Santos, 2017; Constantino, 2016).

As principais problemáticas encontradas no sistema prisional, que consequentemente afetam diretamente a saúde física e mental das pessoas inseridas nele, estão relacionadas à superlotação, o elevado índice de reincidência carcerário, a ociosidade e as condições de vida e higiene precárias. Além do mais, a negação de assistência jurídica e atendimento médico, odontológico e psicológico, o ambiente propício para a ocorrência de violências, o elevado consumo de substâncias psicoativas (SPA) e os efeitos biopsicossociais que o âmbito prisional produz, fortalecem mais a necessidade de uma assistência à saúde física e mental que supra as demandas dessa população (Dourado, 2019; Machado, 2014).

Frente ao contexto de restrição e violação dos direitos humanos no sistema prisional, faz-se necessário conhecer os fatores que poderiam desencadear o sofrimento e adoecimento mental, fortalecendo a necessidade de estudos que abordem a saúde mental de mulheres em privação de liberdade para que uma assistência de qualidade seja prestada. Portanto, o presente estudo tem por objetivo conhecer a percepção de mulheres em privação de liberdade acerca de sua saúde mental.

\section{Metodologia}

O presente estudo é do tipo descritivo de abordagem qualitativa. A coleta de dados foi realizada por meio da aplicação e gravação de entrevistas semiestruturadas. O público-alvo foram mulheres que se encontravam em privação de liberdade em um Presídio Regional de uma cidade do sul do Rio Grande do Sul. Os dados foram coletados durante dois dias do mês de janeiro de 2018, em uma sala disponibilizada pela administração do presídio na galeria feminina da instituição prisional.

Foram entrevistadas oito mulheres. A coleta de dados se deu por meio da técnica snowball (bola de neve), na qual cada participante foi indicando outras mulheres a participar, até que o ponto de saturação fosse alcançado. O ponto de saturação ocorreu quando as informações de novas entrevistas se tornaram repetitivas e as entrevistas já não traziam novas informações para a pesquisa (Bardin, 2011). A primeira participante foi indicada pela Assistente Social da instituição prisional. Os critérios de inclusão foram: ser mulher, ter mais de 18 anos e encontrar-se em regime fechado no sistema prisional por no mínimo um mês.

A análise dos dados foi realizada a partir da Análise Temática, proposta por Minayo (2010), a partir dos dados brutos retirados da coleta. As entrevistas foram transcritas e identificadas e as informações analisadas em três etapas: pré-análise, exploração do material e tratamento dos dados. As participantes foram identificadas pela letra M, seguido de numeração correspondente a realização da entrevista, garantindo assim o anonimato. Após essa etapa, foram feitas a leitura e a organização dos dados para que pudessem ser interpretados e agrupados em temáticas. Os dados foram agrupados para análise e divididos em quatro temas a serem apresentados: Perfil e condições de saúde física de mulheres em privação de liberdade, Percepção sobre saúde mental e sentimentos relacionados à saúde mental, Redes de apoio e sentimentos relacionados ao apoio, O dia-a-dia de vivências e convivências e as técnicas de enfrentamento do cotidiano prisional e sugestões de atividades.

O trabalho foi submetido à Plataforma Brasil e teve a aprovação do Comitê de Ética e Pesquisa da Faculdade de Enfermagem da Universidade Federal de Pelotas/UFPel sob o parecer de número 2.328.670. Os participantes assinaram o Termo de Consentimento Livre e Esclarecido (TCLE). Os princípios éticos foram assegurados conforme a Resolução ${ }^{\circ}$ 466/12, do Conselho Nacional de Saúde do Ministério da Saúde, que trata da pesquisa envolvendo seres humanos (Brasil, 2012). Foi considerada, também, a resolução do Conselho Federal de Enfermagem (COFEN) 311/2007, Capítulo III do Código de Ética dos Profissionais de Enfermagem (2007), no que diz respeito aos Deveres, nos artigos 89, 90 e 91 e 92 , e às 
Proibições, nos artigos 94 e 98 (Brasil, 2007).

\section{Resultados}

As mulheres desta pesquisa tiveram faixa etária entre 21 e 59 anos, em relação ao estado civil observou-se que quatro eram solteiras, três tinham companheiro que também estavam cumprindo pena na instituição e uma era viúva. O nível de escolaridade variou de ensino fundamental ao superior completo, sendo a maioria delas com médio incompleto. Quanto a sua profissão três eram autônomas, uma atendente de enfermagem, uma empresária, e três sem nenhum vínculo empregatício e profissão.

Sobre ser mãe, a maioria delas relatou ter filhos e que os mesmos se encontravam sob cuidado de familiares. Acerca das condições crônicas de saúde, elas apresentaram hipertensão, gastrite, sífilis e HIV e todas realizam tratamento medicamentoso diariamente. Quanto ao uso de substâncias psicoativas três mulheres relataram nunca terem utilizado nenhuma substância, sendo cocaína e maconha as mais utilizadas pelas mulheres que afirmaram o uso.

A seguir veremos como estas mulheres vivenciam a privação, sendo possível observar que elas oscilam os seus sentimentos durante este período, tendo um forte impacto na sua saúde mental.

[...] eu acho que eu ando bem mais agitada [...] é eu acho que agora eu ando com a minha, minha mentalidade mais flor da pele, então, eu ando muito irritada porque "tô" louca pra ir embora, por isso, nunca chega, parece que nunca vai chega, mas eu acho, eu sou tranquila, acho. (M1)

[...] olha eu acho que não é muito boa não! (risos) [...] que eu tenho muitas coisas dentro da minha cabeça assim, eu tenho, eu sei que eu tenho uma mania de o tempo todo pensando em desgraça, que tudo de ruim vai acontecer comigo, vai acontecer com a minha família, o tempo todo. (M2)

[...] eu "tô", eu avalio que eu não "tô" legal, avalio que a minha cabeça tá bem fraca, que a minha mentalidade já não tá mais a mesma, do que tava tipo a três meses atrás, que já "tô" num estágio bem avançado assim, quase precisando me internar [...] parece que eu tô enlouquecendo sabe, parece que eu tô saindo fora, parece que meu pensamento não tá legal, eu não sei explicar entendeu [...] porque eu não aguento mais, seis meses já tá assim, eu fico pensando meu Deus do céu, eu devo ficar aqui seis anos eu morro, eu não aguento mais, "tô" no meu limite (M3)

[...] ah eu me sinto mais assim é com vontade de ir embora pra rua né mais (risos) sair daqui logo. Vontade de ir embora logo, ser livre. (M4)

[...] eu acho que pesou muito em relação de eu tá presa, eu deito, eu acordo, sempre com aquela coisa que não é aqui que eu tenho que tá, isso pesa muito. Nada se resolve [...] então isso aí, bah, eu deito e acordo sempre com aquela coisa, isso aí pra mim, mentalmente, pesou muito. (M8)

Pode-se observar que essas mulheres vivenciam sentimentos que perpetuam o cárcere como a saudade, solidão, choro, angústia, preocupação, desânimo, agitação, irritação, isolamento e medo, o que pode acarretar um evento traumatizante e sofrido.

[...] Da minha família só tenho saudade ... só saudade [...] tenho bastante, bastante, tenho ... principalmente porque eu tô longe da minha família toda ... o tempo todo (M2)

[...] principalmente em relação aos meus filhos, eu sinto muita, muita saudade deles assim, é incomparável, eu nunca pensei sabe, é só isso sabe se não eu tava na boa por ta presa, pelo o que eu fiz, só a falta deles assim, tá me deixando louca sabe assim [...] A saudade é o pior sentimento do mundo. Dói muito, a saudade que eu tenho dos meus filhos, nada supre, nada supre, nada, nada mesmo. (choro) (M3)

[...] não, só fico assim com um aperto no peito de vontade de ir embora, quando não sabe noticia dos filhos [...] cai a ficha da gente aqui dentro, preocupação, saudade da casa da gente, dos filhos, dos netos [...] com as minhas filhas principalmente a gente morava junto né. Sente muita falta [...] Angústia, angústia. Muita falta de casa né. Dá família 
da gente. Imagina, tua casa totalmente diferente, teus filhos, teus netos ... vem pra cá não vê ninguém, fica afastado, até os amigo da gente né. (M4)

[...] eu fico preocupada só com a minha mãe né, porque ela não vem aqui, fico preocupada com a minha mãe e meu pai só [...] é as únicas pessoas preciosas que eu tenho (M5)

\section{[...] agora no final que tá pesando mais, porque eu tô longe da família, a saudade aperta né, é meio difícil. (M7)}

[...] saudade da minha filha, porque né, só ela que eu tenho né [...] é a falta de casa, a falta de tudo [...] o que pesa mais é tá longe dela. (choro) (M8)

Observa-se que estas mulheres apresentam sintomas depressivos como desanimo e tristeza, além de relatarem pensamentos e atos suicidas, que são atitudes relacionadas aos sintomas depressivos.

[...] eu tava muito triste, eu cheguei a ficar cinco dias sem comer nada aqui dentro, porque eu tava assim de um jeito que não tinha vontade de nada, agora faz uns dois dias que eu tô melhorando [...] mais é a solidão mesmo, o abandono assim, mais solidão mesmo (choro) [...] eu choro pra aliviar, choro pra todo o lado. Vou lá e choro, choro, choro (M2)

[...] ah "cê"” fica desanimada, tem dias que "cê" não quer falar com ninguém, que "cê"” chora, "cê" se tranca. (M6).

[...] pensei já, mas nunca tentei, mas pensei assim que não tinha mais vontade de nada assim. [...] ah, ultimamente eu pensei ... um mês atrás mais ou menos [...] ai a gente pensa né já tô aqui, ninguém dá bola pra mim né, o que eu tô fazendo? Mas agora que as meninas da cela me ajudaram um pouco assim. (M2)

[...] não vou dizer que eu não tentei, porque no início, assim que eu caí presa no Madre, eu tentei me matar mesmo, mas depois daí, no outro dia depois que eu fiz a besteira, que Graças a Deus não aconteceu nada, que eu pensei o que vai adiantar, o que que ia adiantar né, a minha família ia ficar sofrendo, meus filhos também, mas Graças a Deus não deu nada [...] eu peguei, quebrei a gilete e tentei cortar os pulsos. (M7)

As mulheres desta pesquisa apresentam diferentes redes de apoio neste momento de privação, assim como uma rede de apoio diferenciada para cada uma delas. Algumas mulheres encontram nos familiares e amigos um apoio muito importante no momento em que eles vão realizar visitas e levar alguns pertences, em contrapartida, outras apenas recebem utensílios e pertences através de outras pessoas e também mulheres que não recebem nenhum tipo de apoio de familiares e amigos, relatando assim um afastamento de suas relações anteriores a privação.

[...] eu só tenho visita só do meu marido, mas a minha família sempre manda as minhas coisas, vem de 15 em 15 dias [...] eu não tenho visita, aqui eu não tenho visita. Só a minha sogra que vem [...]. Vem ver meu marido, na carteirinha é ele, mas todo mundo se vê (risos) [...] fico tranquila, porque né ... fiz tenho que pagar! (M1)

[...] eu tinha um companheiro e ele vinha me visitar aqui dentro ... ele era única pessoa que eu tinha sabe, não tinha mais ninguém aqui [...]aí foi embora ... foi embora ... minha família mal fala comigo [...] Da outra vez ele ficou o tempo todo, não faltou nenhuma visita, ai eu vim presa de novo, depois de tudo é que nós viemos os dois presos juntos né, ele deu a sorte de ir embora, beleza né, mas dai ele foi pra rua virou as costas pra mim e foi embora (choro) [...] Eu tô com muito sentimento de ódio assim, muito mesmo, queria tirar isso ... é difícil! (M2)

[...] Só a minha filha e meu guri que vem, meu guri agora faz tempo que não aparece, mas a minha filha sempre vem, a minha pequena né [...] ah eu me sinto muito bem, mas ela (filha) sempre me traz notícias de todos, sempre me traz notícias [...] eu entendo a situação deles né, o meu guri trabalha, se não ele tem que faltar o serviço, então ele não vem, ai fica difícil né [...]Tudo eles trazem, tudo. (M4)

[...] eu tenho apoio da minha família total [...] eu tenho apoio da minha mãe, na verdade quando cê tá presa, cê mesmo se apoia, não precisa ninguém te apoiar [...] Eu tenho que mandar recado quando vem uma pessoa na terça ou no sábado, mando pra ligar pra minha irmã, a pessoa empresta tanto, a minha irmã manda o dinheiro aí a pessoa traz o dinheiro pra cantina [...] minha família, posso fica 10 anos, 12 anos e eu vou ter eles [...] Eu não me importo 
de não receber visita, não me importo, eu nem quero que a minha irmã, minha mãe venha, minha irmã sair lá do Mato Grosso, andar mais de quatro mil quilômetros pra vim, não precisa. Eu fiz, eu tenho que cumprir e ir embora, acho que cê não tem que trazer tua família pro presídio. (M6)

[...] não. Nenhuma visita, nem eu, nem ele (marido) [...] tive também visita assistida com a minha filha [...] se não fosse a reserva, ninguém ajuda nada, ninguém te oferece um real, te manda um sabonete, não te manda nada, os amigos somem, aqueles que comiam churrasco na tua casa, tudo some. É bem assim que funciona. Pelo menos pra mim tá sendo, isso aí pesa também porque, poxa cadê todo mundo? Todo mundo vira as costas, a gente não é nenhum bicho porque foi preso, tá certo que a gente tá errado, e muito errado, mas não tem que condenar, porque todo mundo tem um defeito [...] (M8)

Em relação a vivência e convivência dessas mulheres no dia a dia da privação de liberdade, elas relatam uma relação saudável para que se tenha um viver mais tranquilo e que favoreça o bem-estar de todas, assim como a criação de um apoio mútuo entre elas, principalmente em momentos mais tristes e estressantes. Porém se percebe em algumas falas que algumas mulheres restringem suas conversas com as parceiras de cela, evitando muito contato com outras galerias, para evitar fofocas ou confusão.

[...] ah eu sou uma presa tranquila assim, sou bem ... no que posso ajudar elas eu ajudo, o que eu não posso também não saio do limite. As guardas não me chamam a atenção, graças a Deus. Sou bem tranquila! [...] ah eu me dou com todo mundo, todo mundo. (M1)

[...] Só com as da minha cela, o resto da galeria não se mistura porque é muita fofoca, muita confusão [...] pra mim é coisa assim, eu me dando bem com as meninas da minha cela o resto é só bom dia, boa tarde, tchau e deu, não se mistura. [...] é tranquila, eu não me misturo [...] aqui a gente tá junto o tempo todo, não tem como a gente fugir, não tem o que fazer, então é ceder né [...] cada uma tem um jeito, só saber levar que dá tudo certo. (M2)

[...] é tranquilo [...] as relação lá da cela é bem tranquila, elas sabe que eu "tô" assim, elas são bem companheiras assim mesmo, elas tentam me ajuda quando vê que eu "tô" mais abatida, mas é tranquila, no dia-a-dia assim é tranquila. (M3)

[...] normal, é como se eu tivesse numa casa, convivendo com outras pessoas, mesmo que não seja família, a gente faz uma família aqui dentro. Se acostuma a ficar todo mundo junto (M4)

[...] no início eu estranhei um pouquinho, porque aqui é totalmente diferente de lá pra cima (Madre), lá pra cima a gente não tem tanto contato assim com os guardas, aqui já tem mais contato porque elas entram dentro da galeria [...] as gurias da galeria no caso, eu me dou bem com todas, não tenho problema com nenhuma, no início quando eu cheguei aqui fiquei meio assim né, porque eu sou de fora, recém chegando, fiquei meio assim, não, vou ficar no meu canto e quem querer conversar comigo, converso, se não conversar, foi assim que eu consegui meu espaço e Graças a Deus me dou com todo mundo, não tenho problema com ninguém. (M7)

Em relação às atividades que estas mulheres realizam para enfrentar o seu dia-a-dia, observa-se que algumas participam de um projeto que é realizado dentro do presídio, que ensina práticas de bordado, culinária, crochê, tricô. Outras mulheres relatam que realizam outras atividades como assistir televisão, escutar rádio, realizam a limpeza da cela, em contrapartida observa-se que uma das mulheres utiliza o tempo para dormir, para ver se os dias dentro do presídio passam mais rápido.

[...] eu rezo bastante e eu sempre "tô" vendo alguma coisa [...] eu bordo, faço rapadura, faço doce, eu nunca "tô" parada, acho que é isso que eu consigo passar o tempo. [...] nós temos um projeto Amor [...] é tricô, bordado [...] é muito legal aquilo, eu participo, eu praticamente todas as coisas eu participo (risos) (M1)

[...] eu aprendi a fazer crochê num curso que teve aqui no presídio, elas me ensinaram, foi muito bom [...] era muito bom aquele curso mesmo [...] é o que eu "tô" fazendo pra me virar aqui dentro [...] que elas me deram umas linhas, eu faço guardanapo, vendo e assim eu vou comprando as coisas pra mim ir se virando. (M2) 
[...] de dia eu passo dormindo [...] ultimamente eu "tô" passando mais dormindo, tentando ver os dias passar, pra ver se passa logo isso [...] eu não consigo fazer outra coisa, eu não consigo me prender a nada, eu não consigo focar em nada, eu não consigo. (M3)

[...] de dia a gente assiste tv, a gente conversa, as vezes a gente pega umas folhas e joga STOP (risos) escutamos rádio, às vezes não tem o que fazer, vamo limpar a cela, vamo limpa, levantamo tudo pra cima, limpamo tudo, a gente inventa as vezes né coisa pra fazer (risos). Agora elas tão de recesso, mas antes tinha o curso de crochê, que elas disponibilizam aqui pra nós curso de crochê, de tricô, ai elas dão material e a gente se interte na cela fazendo, eu fazia crochê, fazia tricô, agora abandonei um pouquinho, mas tá lá, tudo o que eu fiz (risos) [...] tu pega um livro ali, tu lê um monte página quando vê já passou o dia e tu nem percebeu. (M5)

Essas mulheres também relataram a importância de serem realizadas outras atividades durante o período de privação de liberdade, entre elas o lazer, ginástica e dança. Também afirmam a necessidade de outras atividades para o cuidado a saúde, cursos profissionalizantes, para que tenham oportunidades ao saírem do sistema prisional, e também nota-se a preocupação delas em relação a educação, visto que elas relatam desejo por uma oportunidade de terminarem o ensino fundamental e médio.

[...] é a gente tá aqui sem fazer nada praticamente, termina os estudo né, seria bacana pra quem não tem [...]seria legal se o nosso pátio fosse de manhã e ver se alguém pelo menos uma vez na semana viesse trazer uma ginastica, uma dança, alguma coisa, que a gente fica muito sem fazer nada [...]podia soltar a feminina de manhã pra uma ginástica, acho que a gente vai gostar, todas nós. (M2)

[...] acho que palestras pra elas saberem mais. [...] tema de drogas [...]acho que um incentivo pra parar de usarem droga, eu acho [...] Eu acho que também a enfermaria tinha que vim mais pra os teste rápidos, pra saber mais sobre, porque a gente não sabe ... vim mais aqui dentro [...] (M1)

[...] acho que elas podiam, sei lá, dar umas cartas pra nós jogar, uns jogo de dama, umas coisas assim [...] Ela (prefeita) venho, ai ela disse que ia fazer curso pra gente sair daqui, trabalhar, ser autônoma no caso né, pra gente abrir o nosso próprio negócio, pra não ter essa discriminação com o preso, que não sei o que e não sei o que ... Eu acho que seria uma boa né, porque até agora eu não vi nada (risos). (M5)

[...] porque não faz um programa pra alfabetizar? Porque não coloca uma EAD a distância no presídio? Tem gente que vai ficar aqui cinco, seis anos, sai daqui formado. Porque que não fazem isso? Porque não tem aqui faculdade pública? Porque não vem? Não faz um projeto? Porque quem tem o terceiro ano, se forma, sai daqui formado, entendesse? Em três, quatro anos cê se forma, cê vai ficar três, quatro, preso. Tem que pensar: Ah vou formar, vou sair pra rua e fazer isso [...] Acho que o mínimo que a cadeia tem que dar é educação, faz concurso, coloca uma professora aqui dentro, as vezes a pessoa vai começar a ler um livro, eu gosto disso aqui, outra vai fazer um crochê, ai sair lá fora e fazer, pra vender na rua ajudar, fazer um pano de prato [...]Se o diretor dentro da cadeia quer mudar o convívio das presa tem que dar educação, tem que ter escola, aprender a ler, ter um incentivo, uma palestra Mas se você não tem incentivo, cê não faz nada, cê só vai criar mais um marginal na sociedade [...] De dez salvar um, é uma bala a menos na sociedade. Essa é a conta. (M6)

\section{Discussão}

O perfil dessas mulheres que vivem em cárcere vai ao encontro de outra pesquisa realizada no Brasil, que mostra que a faixa etária encontra-se entre 18 a 29 anos, mais da metade se declara solteira e pouco mais de um terço relata viver em uma união estável (Brasil, 2015)

O nível de escolaridade de mulheres em privação de liberdade no estudo de Pimentel (2015) revelou resultados diferentes, onde elas apresentavam baixa escolaridade não chegando a concluir o ensino fundamental, porém com relação à profissão, o trabalho autônomo de baixa remuneração foi o mais evidenciado também. Já, Flores e Smeh (2018) encontram em seu estudo a maioria das mulheres pesquisadas com o ensino fundamental e/ou médio completo e profissões bem definidas, embora não identificando presença/ausência de vínculo empregatício.

O resultado acerca da maioria das mulheres entrevistadas serem mães apenas confirma o já observado nas penitenciárias brasileiras segundo o Levantamento Nacional de Informações Penitenciárias - Infopen, 74\% das mulheres em 
privação de liberdade são mães (BRASIL, 2017). Condição esta que possibilita culmina em crianças e adolescentes que se desenvolvem sem a presença das mães. Ademais, os resultados mostram que os filhos ficam com um membro da família, o que demonstra o quanto a situação de prisão não envolve apenas mudanças de rotina da mulher, mas impacta no cotidiano de vida de uma família e que a precariedade das relações familiares e do vínculo estabelecidas durante o cumprimento da pena influencia na possibilidade de se exercer o papel de mãe no contexto prisional (Flores e Smeh, 2019).

Percebeu-se nas falas das participantes que essa mudança de rotina na vida da mulher cárcere, somada ao fato de ficar longe dos filhos e demais familiares é o que potencializa os sentimentos de saudade, solidão, preocupação, irritação e desânimo. Sentimentos estes que contribuem para o fato de que a maioria apresenta sintomas de estresse e depressão, assim como encontrado no estudo de Santos et al (2017a), realizado com mulheres cárceres no Rio de Janeiro.

O estudo de Constantino et al (2016) corrobora ao constatar, nas penitenciárias do Rio de Janeiro (RJ), que a situação de cárcere gera um impacto maior na saúde mental das mulheres quando comparado aos homens na mesma situação, sendo a preservação do vínculo familiar um fator de proteção. Assim, compreende-se a importância de facilitar o direito à visita, bem como construir mecanismos que mantenham e consolidem os vínculos familiares das mulheres cárceres. Por este motivo, Flores e Smeh (2018) defendem a necessidade de se investir na mediação de um ambiente prisional menos hostil, com acolhimento no intuito de favorecer as relações interpessoais e promovendo maior vínculo dos familiares, em especial, dos filhos. O que fortalece a maternidade, amenizando os sentimentos de culpa e abandono, tanto na mulher como em seus filhos.

A saúde mental prejudicada destas mulheres em cárcere pode estar relacionada com as condições precárias que os presídios apresentam, como um ambiente insalubre, com superlotação, má alimentação, entre outros. Assim os profissionais devem estar atentos para sintomas de saúde mental, visto que neste ambiente os transtornos são mais prevalentes que na comunidade em geral, principalmente em mulheres (Constantino, 2016).

Pode-se observar também que a saúde dessas mulheres é afetada de diversas formas, principalmente por elas terem características mais vulneráveis como sensibilidade e angustia. Visto que o cárcere é considerado um ambiente hostil, ele favorece os sentimentos de abandono, tristeza, saudade e solidão (Santos, 2017; Ribeiro, 2017). Como discutido anteriormente, percebe-se que é um somatório de fatores que geram sentimentos angustiantes nas mulheres cárceres, pois com a perda da liberdade, os julgamentos, vem o afastamento dos filhos e familiares e a precariedade de muitas prisões.

Esses sentimentos depressivos despertados nas mulheres cárceres pode justificar a prevalência no uso de substâncias psicoativas por parte das mulheres entrevistadas e que vem ao encontro de um estudo realizado no Piauí, onde as que estão em privação de liberdade utilizaram, ao menos uma vez na vida, alguma substância psicoativa, sendo a mais utilizada a maconha, cocaína e crack (Fernandes, 2015). Destarte, esse ambiente precário do sistema prisional faz com que diversos problemas contribuam para o agravamento da realidade que é vivenciada por estas mulheres, como a falta de apoio, condições estruturais e funcionais e os problemas de saúde mental e seus sentimentos, que quando elevados a um nível extremo e não tratados podem levar essas mulheres a pensamentos e práticas suicidas (Abdelaziz, 2017).

Esses pensamentos suicidas podem estar relacionados, como mostra uma pesquisa realizada no norte do Rio Grande do Sul, à quebra ou enfraquecimento dos vínculos com os familiares e principalmente com seus filhos, visto que elas são privadas de realizarem os cuidados destas crianças, gerando um sentimento autopunitivo que afeta diretamente a saúde mental destas mulheres (Soares, 2016). Assim, essas mulheres se sentem duplamente isoladas, por viverem privadas não só do convívio com outras pessoas, como dos familiares e cuidado com os filhos, tornando este momento de privação traumatizante devido aos sentimentos de angustia e culpabilidade que elas vivenciam (Castanho, 2015).

Dentro desse contexto de sofrimento durante o cárcere, a possibilidade da visita de amigos e familiares faz com que essas mulheres se conectem com outras realidades, tendo conhecimento e acompanhando a rotina destes fora da prisão. Essas visitas fazem com que elas passem pelo tempo de pena com menos sofrimento e mantendo-as próximas às pessoas queridas, 
mesmo que à distância (Pereira, 2016). Porém, Brasil (2008) apresenta uma situação enfrentada pelas mulheres, em particular, o afastamento de seus familiares e de seus companheiros, tendo em vista que mais de $60 \%$ das mulheres em privação de liberdade não recebem visitas. O motivo para tal é o fato de serem vistas como não merecedoras do contato com os familiares como forma de punição dupla: pelo delito que cometeram e por não estarem cumprindo seu papel social de mãe, dona de casa e responsável pelo cuidado da família. Esse estigma não vem apenas da sociedade, ele está presente também nas famílias, o que afeta profundamente a imagem social desta mulher (Becker, 2016).

No contexto do cárcere, a família é a principal instituição para o fornecimento de suporte, de socialização e organização para as mulheres. Mas os entraves para a visita perpassam desde questões socioeconômicas dos familiares em dirigirem-se até a prisão, desconforto pela obrigatoriedade da vistoria invasiva, bem como questões simbólicas em que os homens cônjuges não se sentem obrigados a visitar a mulher cárcere, bem como entraves de locomoção dos abrigos quando possuíam filhos nestes locais. Por outro lado, quando as mulheres não recebem visitas, além dos impactos emocionais do rompimento do vínculo familiar, os insumos básicos que, muitas vezes não são disponibilizados pelo governo, ficam a cargo da rede social da prisão, como funcionários, religiosos, entre outros (Barsinski et al 2014; Silva \& Melo, 2019; Medeiros, 2010).

Manter o vínculo com as pessoas que permanecem vivendo em liberdade possibilita a essas mulheres uma rede de apoio tanto no carinho, escuta e acolhimento, como também de manter as necessidades básicas no auxílio com produtos básicos de higiene, garantindo o mínimo necessário de conforto. Nesse contexto, o apoio mútuo das careceres durante o período intramuros foi percebido no presente estudo, como também compartilhado por Silva e Tiellet (2020), que, embora haja momentos conflituosos, o ambiente cotidiano geralmente é tranquilo. Corroborando, Silva e Melo (2019) complementam na perspectiva do relacionamento homoafetivo como um conforto diante do abandono conjugal.

Segundo o Grupo de Trabalho Intersetorial (2007), as penitenciárias femininas brasileiras, na sua grande maioria, ocupam prédios que mantém a estrutura física que já eram consideradas inadequadas, por vezes desativadas por questões de salubridade ou segurança, que anteriormente abrigavam homens e foram apenas reformados sem considerar às especificidades da mulher, tampouco a função social da pena. Ou seja, instalações, muitas vezes, insalubres, desprovidas de um mínimo conforto, com instalações deterioradas e sem espaço físico adequado para áreas destinadas a recreação, as práticas laborativas e educacionais, ao lazer, a berçários e a creches. Além de não terem acesso a produtos essenciais como absorventes íntimos, bem como privadas dos direitos sexuais (visita íntima) garantidos nas penitenciárias masculinas.

Queiroz (2015) também aborda essa diferença na realidade prisional masculina e feminina, relatando o dia a dia da mulher encarcerada e destaca que o poder público coloca as mulheres em um pacote padrão muito parecido com o masculino na prisão. Ignoram lidar com mulheres, que menstruam, que vivenciam a maternidade e demais especificidades femininas.

No que concerne à educação e ao aprimoramento profissional das pessoas presas no Brasil, é garantido o acesso à Educação Básica e ao Trabalho por meio do artigo 205 da Constituição Federal de 1988, como também pela Lei de Diretrizes e Bases da Educação (n 9394/96) (Brasil, 1988; Brasil, 1996). Todos os presos que desejam estudar intramuros, a oferta da Educação Básica às pessoas em situação de privação de liberdade é uma obrigação do poder público (Pinel, 2017). Somada à resolução n²/2010 do Conselho Nacional de Educação, que dispõe sobre as Diretrizes Nacionais para a oferta de educação para jovens e adultos em situação de privação de liberdade nos estabelecimentos penais (Brasil, 2010). Embora as garantias legais existam, não é o que ocorre na prática dos presídios brasileiros, o que se pode constatar nas falas das mulheres desde estudo que relatam a falta de cursos profissionalizantes, resultado compartilhado com Silva e Tiellet (2020).

Por fim, segundo Shultz, Dias e Dotta (2020), o ambiente prisional pode produzir, desencadear ou agravar os problemas de saúde das mulheres cárceres. A limitada oferta de serviços sociais direcionados à educação, ao esporte, ao lazer e à área ocupacional impactam nas condições de vida nos presídios. Uma vez que são atividades essenciais para amenizar os danos provenientes do confinamento, protegendo e promovendo a saúde física e emocional dessa população. As condições 
atuais dos presídios femininos demonstram a fragilidade organizacional e o escasso comprometimento dos gestores na promoção da garantia dos direitos e melhor vivência durante a reclusão das mulheres.

\section{Considerações Finais}

Percebe-se o quanto a falta de liberdade vem acompanhada de dificuldades para essas mulheres, em um movimento de consequências que para elas, por vezes, parece não ter fim. Destarte, acredita-se na importância do acompanhamento das mulheres cárceres por profissionais de saúde preparados para lidar com as particularidades desse contexto e objetivando não apenas a saúde física, mas a saúde mental, bem como as relações sociais e familiares delas. Proporcionar uma educação em saúde para que elas compreendam a importância do autocuidado e o quanto isso impactará no futuro fora da prisão. Ademais, recai nessa mesma atenção, a necessidade de ofertar cursos de capacitação e aprimoramento para, além de estarem melhores qualificadas para o mercado de trabalho após o cumprimento da pena, desencadear o sentimento de autodesenvolvimento durante os dias intramuros.

Sabe-se o quanto a população cárcere é vulnerável, tanto no interior da prisão, como fora desta, pois lá sentem o peso da falta de liberdade e toda a precariedade do sistema penitenciário. Já, fora deste, sentem o preconceito da sociedade. Portanto, faz-se imprescindível a formulação de políticas públicas e redes de apoio fortalecidas, que proporcionem melhor qualidade de vida a essas mulheres durante o cumprimento da pena, em especial no fortalecimento dos vínculos familiares, para que tenham saúde física e emocional de perpassarem esse período com oportunidades concretas de se desenvolverem e conquistarem seus espaços quando em liberdade.

Durante a discussão, pode-se perceber e reconhecer as limitações do presente estudo no que se refere aos detalhes não captados durante as entrevistas, bem como por outros métodos de coleta e que poderiam contribuir no melhor conhecimento acerca das especificidades do local e seu cotidiano. Porém, este não foi o objetivo do presente estudo que, acredita-se ter sido suprido, uma vez que se pode conhecer o impacto que as relações familiares ocasionam na auto percepção das mulheres aos seus sentimentos e, consequentemente, sua saúde mental. Com isso, espera-se que este estudo sirva de alerta e incentivo para o desenvolvimento de ações que proporcionem melhor qualidade de vida às mulheres cárceres.

Sugere-se novos estudos que abordem ações e iniciativas existentes para a melhoria da qualidade em saúde dessas mulheres, na tentativa de amenizar o impacto negativo da fragilidade das relações familiares no cotidiano delas. Bem como, o estudo das demais interfaces do contexto prisional feminino, sempre assegurando dar voz às mulheres intramuros.

\section{Referências}

Abdelaziz, J.S. (2017). O uso de medicação psicotrópica por mulheres presas no distrito federal e as interfaces com a política nacional de atenção integral das pessoas privadas de liberdade no sistema prisional. [Dissertação de Mestrado, Universidade de Brasília]

Barcinski, M.; Lermen, H.S, Campani, C.; \& Altenbernd, B. (2014). Guerreiras do cárcere: uma rede virtual de apoio aos familiares de pessoas privadas de liberdade. Temas em psicologia, 22(4), 929-940. http://pepsic.bvsalud.org/scielo.php?script=sci_arttext\&pid=S1413-389X2014000400019

Bardin, L. (2011) Análise de Conteúdo (1ed.) São Paulo: Edições 70.

Becker, A.; Spessote, D.V.; Sardinha, L.S.; Santos, L.G.M.; Chaves, N.N.; \& Bicalho, P.P.G. (2016). O cárcere e o abandono: prisão, penalização e relações de gênero. Revista Psicologia, Diversidade e Saúde, 5(2), 141-154. https://doi.org/10.17267/2317-3394rpds.v5i2.1050

Brasil (2010). Resolução nº 2 de 19/05/2010 / CNE - Conselho Nacional de Educação. Diretrizes Nacionais para a oferta de educação para jovens e adultos. Dispõe sobre as Diretrizes Nacionais para a oferta de educação para jovens e adultos em situação de privação de liberdade nos estabelecimentos penais.

Brasil. (2015) Instituto de Pesquisa Econômica Aplicada. Reincidência Criminal no Brasil: Relatório de Pesquisa. 160p.

Brasil. (2017). Conselho Nacional de Justiça. Levantamento Nacional de Informações Penitenciárias - INFOPEN MULHERES. Departamento Penitenciário Nacional. http://depen.gov.br/DEPEN/depen/sisdepen/infopen-mulheres/infopenmulheres_arte_07-03-18.pdf/view 
Brasil. Ministério da Justiça. Mulheres encarceradas consolidação dos dados fornecidos pelas unidades da Federação, 2008. https://www.justica.gov.br/news/estudo-traca-perfil-da-populacao-penitenciaria-feminina-no-brasil/relatorio-infopen-mulheres.pdf

Brasil. Ministério da Saúde (2012) Resolução nº 466 de 12 de dezembro de 2012: Trata de pesquisas em seres humanos e atualiza a resolução 196. Conselho Nacional de Saúde.

BRASIL. Constituição (1988). Constituição da República Federativa do Brasil

Castanho, A.C.S. (2015). A experiência de ser mãe na prisão. [Dissertação de Mestrado, Instituto Universitário ciências psicológicas, sociais e da vida] Conselho Federal de Enfermagem. (2007) Resolução COFEN n 311, de 08 de fevereiro de 2007. Aprova a reformulação do Código de Ética dos Profissionais de Enfermagem [Internet].

Constantino, P.; Assis, S. G.; Pinto, L. W. (2016) O impacto da prisão na saúde mental dos presos do estado do Rio de Janeiro, Brasil. Ciência \& Saúde Coletiva, 21(7), 2089-2099. https://doi.org/10.1590/1413-81232015217.01222016

Constantino, P.; Assis, S.G.; \& Pinto, L.W. (2016) O impacto da prisão na saúde mental dos presos do estado do Rio de Janeiro, Brasil. Ciência saúde coletiva 21 (7). https://doi.org/10.1590/1413-81232015217.01222016

Dourado, J.L.G.; \& Alves, R.S.F. (2019) Panorama da saúde do homem preso: dificuldades de acesso ao atendimento de saúde. Academia Paulista de Psicologia, 39(96), 47-57. http://pepsic.bvsalud.org/scielo.php?script=sci_arttext\&pid=S1415-711X2019000100006\&lng=pt\&tlng=pt.

Fernandes, J. (2015) Assembleia Legislativa do Estado do Rio Grande do Sul. Comissão de Cidadania e Direitos Humanos. Subcomissão do Sistema Prisional do Estado do Rio Grande do Sul. Relatório da Subcomissão com diagnóstico do sistema prisional do estado do Rio Grande do Sul, análise crítica e proposições.

http://www.al.rs.gov.br/FileRepository/repdep_m505/CCDH/Relat\%C3\%B3rio\%20Final\%20Subcomiss\%C3\%A3o\%20do\%20Sistema\%20Prisional\%20RS.P $\mathrm{DF}$

Ferrari, I.F., Simões, V.F.N. (2019) Female inmates and their children: criminal judicial system in perspective. Psicologia Clínica 31(3):421-37. http://dx.doi.org/10.33208/PC1980-5438v0031n03A01

Flores, N.M.P.; \& Smeh, L.N. (2018). Mães presas, filhos desamparados: maternidade e relações interpessoais na prisão. Physis 28(4). http://dx.doi.org/10.1590/s0103-73312018280420

Gusmão, M.A.J.X., Terças-Trettel, A.C.P., Nascimento, V.F., Hattori, T.Y., Brescovit, L.E., Anataka, M., Lemos, E.R.S. (2019). Social and family dynamics and vulnerability of incarcerated females. Revista Saúde e Pesquisa; 12(1):159-68. https://doi.org/10.17765/2176-9206.2019v12n1p159-168 https://revistaseletronicas.pucrs.br/index.php/fass/article/view/36887/26505

Lei $\mathrm{n}^{\circ}$ 9.394, de 20 de dezembro de 1996. Lei Diretrizes Nacionais para a oferta de educação para jovens e adultos. Dispõe sobre as Diretrizes Nacionais para a oferta de educação para jovens e adultos em situação de privação de liberdade nos estabelecimentos penais

Machado, N.O.; \& Guimarães, I.S. (2014) A Realidade do Sistema Prisional Brasileiro e o Princípio da Dignidade da Pessoa Humana. Revista Eletrônica de Iniciação Científica. 5(1), 566-581. https://www.univali.br/graduacao/direito-itajai/publicacoes/revista-de-iniciacao-cientificaricc/edicoes/Lists/Artigos/Attachments/1008/Arquivo\%2030.pdf

Medeiros, L.L. (2010). Mulheres e cárcere - Reflexões em torno das redes de proteção social. In Encontro Nacional de História Oral - Testemunhos: História e Política. Universidade Federal de Pernambuco.

Minayo M.C. (2010). Pesquisa Social: Teoria, método e criatividade (29 ed.). Vozes.

Pereira, E.L. (2016). Famílias de mulheres presas, promoção da saúde e acesso às políticas sociais no Distrito Federal, Brasil. Ciência \& Saúde Coletiva, 21(7), 2131-2134. https://doi.org/10.1590/1413-81232015217.16792015

Pimentel, I. S.; Carvalho, L. F. S.; Carvalho, S.; \& Carvalho, C. M. S. (2015). Percepção de mulheres privadas de liberdade acerca da assistência à saúde no sistema penitenciário. R. Interd.8(4), 109-119. https://revistainterdisciplinar.uninovafapi.edu.br/index.php/revinter/article/view/659/pdf_268

Pinel, W. R. (2017). Educação em prisões: um olhar à formação profissional na penitenciária feminina do Distrito Federal [Dissertação de Mestrado , Universidade de Brasília].

Queiroz, N. (2015). Presos que menstruam, a brutal vida das mulheres - tratadas como homens - nas prisões brasileiras (1ed.). Record.

Ribeiro, M.A.T.; \& DEUS, N.M.S.F. (2017) Mulheres encarceradas: a saúde atrás das grades. Revista Psicologia, Diversidade e Saúde, 6(4), 324- 339. http://dx.doi.org/10.17267/2317-3394rpds.v6i4.1708

Santos, M. V.; Alves, V. H.; Pereira, A. V.; Rodrigues, P. D.; Marchiori, G. R. S.; \& Guerra, J. V. V. (2017) Saúde Mental de mulheres encarceradas em um presídio do Estado do Rio de Janeiro. Texto Contexto Enfermagem, 26(2):e5980015. http://dx.doi.org/10.1590/0104-07072017005980015.

Santos, M. V.; Alves, V. H.; Pereira, A. V.; Rodrigues, P. D.; Marchiori, G. R. S.; \& Guerra, J. V. V. (2017a). A saúde física de mulheres privadas de liberdade

em uma penitenciária do estado do Rio de Janeiro. Escola Anna Nery Revista de Enfermagem, 21(2), 1-7. http://dx.doi.org/10.5935/1414-8145.20170033

Santos, M.V.; Alves, V.H.; Pereira, A.V.; Rodrigues, P.D.; Marchiori, G.R.S.; \& Guerra, J.V.V. (2017b) Saúde Mental de mulheres encarceradas em um presídio do Estado do Rio de Janeiro. Texto Contexto Enferm, 26(2):e5980015. http://dx.doi.org/10.1590/0104-07072017005980015

Schultz, A.L.V.; Dias, M.T.G.; \& Dotta, R.M. (2020). Mulheres privadas de liberdade no sistema prisional: interface entre saúde mental, serviços sociais e vulnerabilidade. Textos \& Contextos, 19(2), 1-15. https://doi.org/10.15448/1677-9509.2020.2.36887 
Research, Society and Development, v. 10, n. 11, e398101119820, 2021

(CC BY 4.0) | ISSN 2525-3409 | DOI: http://dx.doi.org/10.33448/rsd-v10i11.19820

SILVA, A.L.A.; \& TIELLET, M.H.S. (2020). Mulheres privadas de liberdade: delito, família, sistema prisional. RELVA. 7(2), 193-212. https://periodicos.unemat.br/index.php/relva/article/view/5074

Silva, J.B., Moraes, M.N., Brandão, B.M.L.S., Freitas, W.M.F., Souto, R.Q., \& Dias, M.D. (2020). Women in deprivation of liberty: narratives of obstetric un(assistance). REME, 24 https://doi.org/10.5935/1415.2762.20200083

SILVA, T.L.O; \& MELO, D.B.D.V. (2019) O direito à visitação e a realidade do sistema prisional feminino brasileiro: O caso da Colônia Penal Feminina do Recife - PE. Seminário Internacional de Pesquisa em Prisão, São Paulo - SP GT 19 - Pesquisando prisão na graduação.

Soares, I.R.; Cenci, C. M. B.; \& Oliveira, L. R. F. (2016). Mães no cárcere: percepção de vínculo com os filhos. Estudos e Pesquisas em Psicologia, 16(1), 2745. http://pepsic.bvsalud.org/scielo.php?script=sci_arttext\&pid=S1808-42812016000100003

Stefano, D., \& Mendonça M.L. (2016). Direitos humanos no Brasil 2016: Relatório da Rede Social de Justiça e Direitos Humanos (1ªed) Outras Expressões. https://br.boell.org/sites/default/files/relatorio2016.pdf

Walmsley, R. (2018) World Prison Population List (12th ed). Institute for Criminal Policy Research https://www.prisonstudies.org/sites/default/files/resources/downloads/wppl_12.pdf 